\title{
Tribological Behaviour of Ti or Ti Alloy vs. Zirconia in Presence of Artificial Saliva
}

\author{
Fabio Alemanno ${ }^{1}$, Veronica Peretti ${ }^{2}$, Angela Tortora ${ }^{1}$ and Silvia Spriano ${ }^{2, *}$ \\ 1 Ducom Instruments Europe B.V., Zernikepark 6, 9747AN Groningen, The Netherlands; \\ f.alemanno91@gmail.com (F.A.); angela.tortora@ducom.com (A.T.) \\ 2 Politecnico di Torino, Corso Duca degli Abruzzi, 24-10129 Torino, Italy; veronica.peretti88@gmail.com \\ * Correspondence: silvia.spriano@polito.it
}

Received: 30 July 2020; Accepted: 26 August 2020; Published: 31 August 2020

\begin{abstract}
Abutment is the transmucosal component in a dental implant system and its eventual appearance has a major impact on aesthetics: use of zirconia abutments can be greatly advantageous in avoiding this problem. Both in the case of one and two-piece zirconia abutments, a critical issue is severe wear between the zirconia and titanium components. High friction at this interface can induce loosening of the abutment connection, production of titanium wear debris, and finally, peri-implant gingivitis, gingival discoloration, or marginal bone adsorption can occur. As in vivo wear measurements are highly complex and time-consuming, wear analysis is usually performed in simulators in the presence of artificial saliva. Different commercial products and recipes for artificial saliva are available and the effects of the different mixtures on the tribological behaviour is not widely explored. The specific purpose of this research was to compare two types of artificial saliva as a lubricant in titanium-zirconia contact by using the ball on disc test as a standard tribological test for materials characterisation. Moreover, a new methodology is suggested by using electrokinetic zeta potential titration and contact angle measurements to investigate the chemical stability at the titanium-lubricant interface. This investigation is of relevance both in the case of using zirconia abutments and artificial saliva against chronic dry mouth. Results suggest that an artificial saliva containing organic corrosion inhibitors is able to be firmly mechanically and chemically adsorb on the surface of the Ti c.p. or Ti6Al4V alloy and form a protective film with high wettability. This type of artificial saliva can significantly reduce the friction coefficient and wear of both the titanium and zirconia surfaces. The use of this type of artificial saliva in standard wear tests has to be carefully considered because the wear resistance of the materials can be overestimated while it can be useful in some specific clinical applications. When saliva is free from organic corrosion inhibitors, wear occurs with a galling mechanism. The occurrence of a super-hydrophilic saliva film that is not firmly adsorbed on the surface is not efficient in order to reduce wear. The results give both suggestions about the experimental conditions for lab testing and in vivo performance of components of dental implants when artificial saliva is used.
\end{abstract}

Keywords: artificial saliva; lubricant; zirconia; titanium alloys; wear

\section{Introduction}

The term biotribology comprises tribological phenomena occurring both in natural tissues and organs of living organisms (such as wear of skin or sliding of eyelids over eye) and after implantation of an artificial device (wear of orthopaedic and dental implants) [1]. This research focused on the last case, and deals with the tribology of materials used for dental implants with a focus on the interface between titanium and zirconia. 
Wear of natural or artificial teeth mainly results from the closed phase of chewing, with food-tooth contact, or eventually from thegosis (sliding teeth into lateral positions) and bruxism (grinding teeth without the presence of food) when direct tooth-tooth contact occurs. Furthermore, nowadays, chemical effects play an increasingly important role in tooth wear, mainly as a result of the large consumption of acid drinks (erosion). Additionally, tooth wear can also result from tooth cleaning or pipe smoking. If moderate tooth wear has significant clinical consequences (aesthetically and functionally), excessive wear can result in unacceptable damage of the occluding surfaces, alteration of the functional path of masticatory movement, dentine hypersensitivity, and pulpal pathology [2]. Biotribology must include both standard tests for materials characterization and specific tests for the simulation of the in vivo environment and mechanical loading [3]. This research focused on the first topic, but with a focus on the selection of the lubricant, which is, in this case, artificial saliva.

Saliva is the lubricant in the human mouth and consists of approximately $98 \%$ water plus a variety of electrolytes and proteins [4]. Salivary proteins can be selectively adsorbed onto solid substrates as well as mucosa membranes exposed to an oral environment, forming a pellicle within a few seconds. Saliva is a source of inorganic ions necessary for remineralization and self-repair capacity because it supplies calcium and phosphate ions. The role of the salivary pellicle is also thought to protect the underlying tooth surface from acid attack because it is a buffer to acids introduced into the mouth [5]. An important function of saliva is to form a boundary lubrication system and to act as a lubricant between hard (tooth) and soft (mucosal) tissues or in dental implants, decreasing wear and reducing friction [5]. It has been widely reported that a salivary film is formed by a layer-by-layer adsorption of salivary proteins and then has a heterogeneous structure consisting of a thin and dense inner layer, able to decrease the friction and wear of teeth, and a thick, highly hydrated and viscoelastic outer layer [6]. The lubricating properties of saliva are presumably related to the strong adhesion strength of the inner salivary film on the tooth surface, which depend on surface roughness, free energy, and the presence of positive or negative surface charges [5]. Harvey et al. observed that the friction coefficient on a hydrophobic substrate was almost an order of magnitude higher than that on a hydrophilic one because of the lower adhesion strength of the salivary film [7]. On the other side, hydrophobic materials in the oral cavity might be more easily cleaned from adsorbed salivary films.

As the transmucosal component in the implant system, the abutment is exposed to the oral cavity and its eventual appearance has a major impact on the aesthetics: using zirconia abutments, aesthetics can be indeed improved. Zirconia abutments are available in two basic designs: one-piece abutment (all parts are made of zirconia in a unit) or two-piece abutment (a secondary metallic component is used as connecting part). Several studies have verified that the fracture strength of two-piece abutments is higher than that of the one-piece design [8,9]. In both cases, the critical issue is severe wear between the zirconia and titanium inducing loosening of the abutment connection and production of titanium wear debris, which can result in peri-implant gingivitis, gingival discoloration, or marginal bone adsorption [10].

A comprehensive description of the tribocorrosion behaviour of different materials coupled in a dental implant can be found in a paper by Sikora et al. [11]. The specific aim of this research was to compare two types of artificial saliva as a lubricant in titanium-zirconia contact and both mechanical (through tribological test ball on disc) and chemical stability (through zeta potential titration curves) of the lubricant film were tested. This investigation is of relevance both for the wear testing of materials and in the case of the clinical use of artificial saliva against chronic dry mouth.

\section{Materials and Methods}

The discs used for tribological tests were made of commercially pure titanium (ASTM B348, Gr2, Titanium Consulting and Trading, Florence, Italy) and Ti6Al4V alloy (ASTM B348, Gr5, Titanium Consulting and Trading, Florence, Italy) and obtained from cylindrical bars (10 $\mathrm{mm}$ in diameter and $2 \mathrm{~mm}$ in thickness). Prior to the tests, the discs were polished using abrasive paper with different grit values (320-2000) and then ultrasonically cleaned in ethanol for $10 \mathrm{~min}$ twice and dried with 
compressed air. The balls used were made of zirconium oxide $\left(\mathrm{ZrO}_{2}\right)$ partially stabilized with yttrium (Y-TZP; Ceratec Technical Ceramics BV, Geldermalsen, The Netherlands; composition: $94.7 \mathrm{wt} . \% \mathrm{ZrO}_{2}$, $5.3 \mathrm{wt} . \% \mathrm{Y}_{2} \mathrm{O}_{3} ; 6 \mathrm{~mm}$ in diameter).

The aim of the research was to compare artificial saliva of different compositions. To do so, two commercial products were used in the form of liquids: Biotène (Biotène ${ }^{\circledR}$ Moisturizing Spray) and BioXtra (Biopharm). Both fluids contain water, xylitol, sodium benzoate, paraben (propylparaben and methylparaben or sodium propylparaben), and sodium saccharin. Moreover, Biotène contains organic corrosion inhibitors: polyethylene glycol 60 hydrogenated castor oil, cetylpyridinium chloride, and the polymer vp/va copolymer. Finally, Biotène contains glycerin, xanthan gum, limonene $(\mathrm{pH}=6.06)$, while BioXtra contains hydrogenated starch hydrolysate, sorbitol, hydroxyethylcellulose, sodium monofluorophosphate, potassium chloride, sodium chloride, magnesium chloride, dipotassium phosphate, calcium chloride, colostrum whey, lactoperoxidase, citric acid, and potassium sorbate $(\mathrm{pH}=7.33)$. No organic corrosion inhibitor is present in BioXtra.

Tribological tests were performed by using a high frequency reciprocating rig instrument (TR-282, Ducom Instruments Pvt. Ltd., Bengaluru, India) with the following parameters: Load $=2 \mathrm{~N}$; Frequency $=30 \mathrm{~Hz}$; Stroke length $=1 \mathrm{~mm}$; Velocity $=60 \mathrm{~mm} / \mathrm{s}$; Temperature $=37^{\circ} \mathrm{C}$; Duration $=60$ min; Lubrication volume $=2 \mathrm{~mL}$. The lubricant (artificial saliva) was measured with a syringe and poured into the reservoir of the disc holder, completely covering the sample. The test was repeated on three different discs (and balls) for each pair of materials and saliva lubricant: the set of experiments allowed us to independently test the different variables. The aim was to independently compare the effect of the different saliva on the same substrate (Ti c.p. or Ti6Al4V) and of the same type of saliva on different substrates. The results were statistically analysed by using the Student's t-test.

Two-dimensional images of the discs and balls were acquired both before and after each test using optical microscopes (AmScope, ME300 Series and Olympus Vanox-T, Leica Microsystems B.V., Amsterdam, The Netherlands, respectively, for observing the discs and balls) in order to measure the length and width of the wear scars (measurements performed by ImageJ software (version 1.52). The samples after tribological tests were rinsed and wiped with ethanol before imaging.

Adsorption of saliva before zeta potential titration and contact angle measurements were performed by placing discs in a 12-well container and each one was covered with $0.5 \mathrm{~mL}$ of saliva. The adsorption phase lasted $1 \mathrm{~h}$ at $37^{\circ} \mathrm{C}$ in the incubator. Subsequently, the samples were left to air dry for two days.

An electrokinetic analyser (SurPASS, Anton Paar, Graz, Austria) was employed for zeta potential titration vs. $\mathrm{pH}$ on the discs after saliva absorption. The surface zeta potential was determined in function of $\mathrm{pH}$ in a $0.001 \mathrm{M} \mathrm{KCl}$ electrolyte solution, varying the solution $\mathrm{pH}$ by the addition of $0.05 \mathrm{M}$ $\mathrm{HCl}$ or $0.05 \mathrm{M} \mathrm{NaOH}$ through the instrument automatic titration unit. The acid and alkaline sides of the curve were obtained in two different steps on two different couples of samples.

Surface wettability by water was determined on the discs after the zeta potential tests through contact angle measurements (sessile drop method, DSA-100, KRÜSS GmbH, Hamburg, Germany). Briefly, a drop $(5 \mu \mathrm{L})$ of ultrapure water was deposited on the material surface and the angle formed with the surface measured by the instrument software.

\section{Results and Discussion}

The coefficient of friction (COF) was measured during the tribological tests of zirconia balls on Ti c.p. or Ti alloy discs under lubrication with different artificial saliva: Biotène (containing organic corrosion inhibitors) and BioXtra (without organic corrosion inhibitors). Figure 1 shows the average friction coefficient as a function of the sliding distance for the four tested material/saliva combinations. 
Ti cp

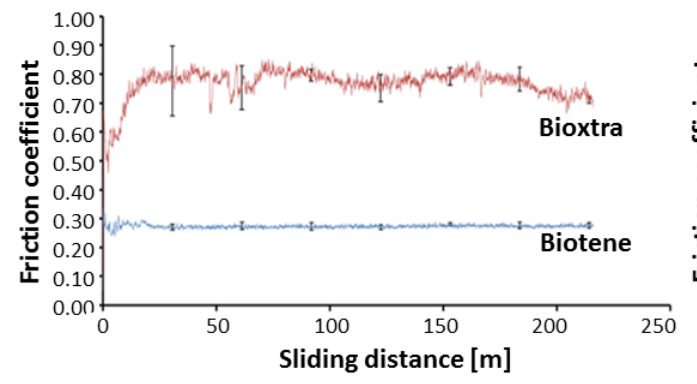

Ti6Al4V

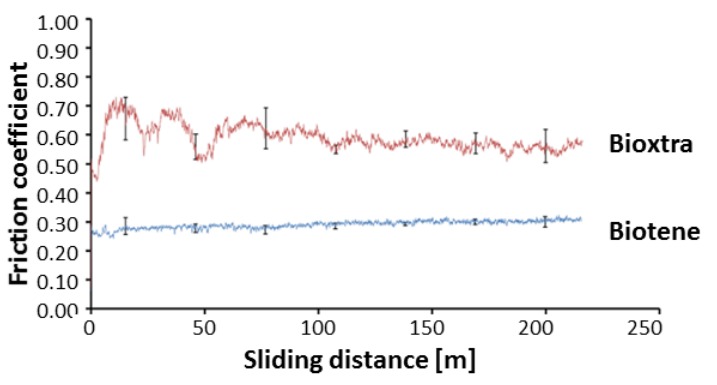

Figure 1. Average COF over sliding distance of Ti c.p. (a) and Ti6Al4V alloy (b) in the presence of Biotène (blue) or Bioxtra (red).

Compared to the BioXtra saliva, Biotène decreased the friction coefficient on both substrates with good lubrication action, as can be seen from the values shown in Table 1: the coefficients of friction of both materials were much lower in the presence of Biotène and they do not differ significantly from each other $(p>0.05$, Student's t-test). The difference between the average friction coefficient of Ti c.p. in the presence of Biotène or BioXtra as a lubricant was statistically significant $(p<0.01)$; the same observation can be made in the case of Ti6Al4V. If we consider BioXtra as a lubricant and we compare Ti c.p. with Ti6Al4V, the difference of the average friction coefficients is again statistically significant $(p<0.01)$. Considering Biotène as a lubricant, the difference between the average friction coefficient of the two substrates was statistically less evident $(p<0.05)$. Furthermore, Biotène showed, by far, lower variability in the friction coefficient. In fact, there was a clear difference in the curve trend: samples lubricated with BioXtra had an initial region with gradual increase of COF, which means a "running-in period" that was much more extensive than those lubricated with Biotène. In this region, an adjustment of the two contacting surfaces occurred by crushing and smearing of the asperities. Then, a second region can be identified, during which COF remains fairly stable in the presence of Biotène, while the COF of the samples lubricated with BioXtra exhibited strong oscillations. After the running-in period, these oscillations may be attributed to the build-up and accumulation of third-body particles in the contact region.

Table 1. Average friction coefficients and standard deviations of all the tested samples.

\begin{tabular}{ccccccc}
\hline Sample & Lubricant & Test $\mathbf{1}$ & Test 2 & Test 3 & Average & Standard Deviation \\
\hline \multirow{2}{*}{ Ti c.p. } & Biotène & 0.27 & 0.27 & 0.28 & 0.27 & 0.005 \\
& Bioxtra & 0.73 & 0.76 & 0.80 & 0.77 & 0.033 \\
\hline \multirow{2}{*}{ Ti6Al4V } & Biotène & 0.29 & 0.30 & 0.28 & 0.29 & 0.011 \\
& Bioxtra & 0.58 & 0.59 & 0.60 & 0.59 & 0.009 \\
\hline
\end{tabular}

A picture of the wear scar was acquired from each disc at the end of each test and a representative set of images is reported in Figure 2 for each of the tested materials. 

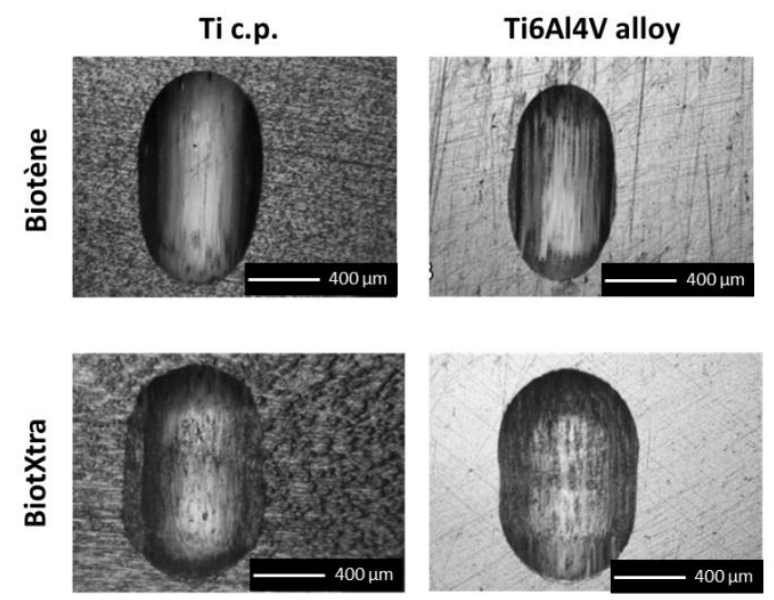

Figure 2. Images of the wear scars on Ti c.p and Ti6Al4V after the tests with Biotène and BioXtra.

In the presence of Biotène (Figure 2), the shape of the scars on both materials was very similar and was almost a perfect ellipse. The edges were regular and well defined. The surface on the bottom of the scars was uniform and almost free of debris. Instead, in the presence of BioXtra (Figure 2), the scars on the two materials resulted in a more irregular elliptical shape. The edges were more jagged and the surface on the bottom of the scars was rough with a considerable presence of debris. In both cases, it can be seen that the grooves on the bottom of the scars showed an oriented texture aligned to the sliding direction. This can be explained by third-body abrasion processes caused by the formation of metal debris due to the ultra-hardness of zirconia.

The area of wear scars in the presence of Biotène was smaller than that in the presence of BioXtra (Figure 3); in particular, that on the titanium alloy was the lowest of them all, according to the higher mechanical resistance of the Ti6Al4V alloy with respect to Ti c.p.

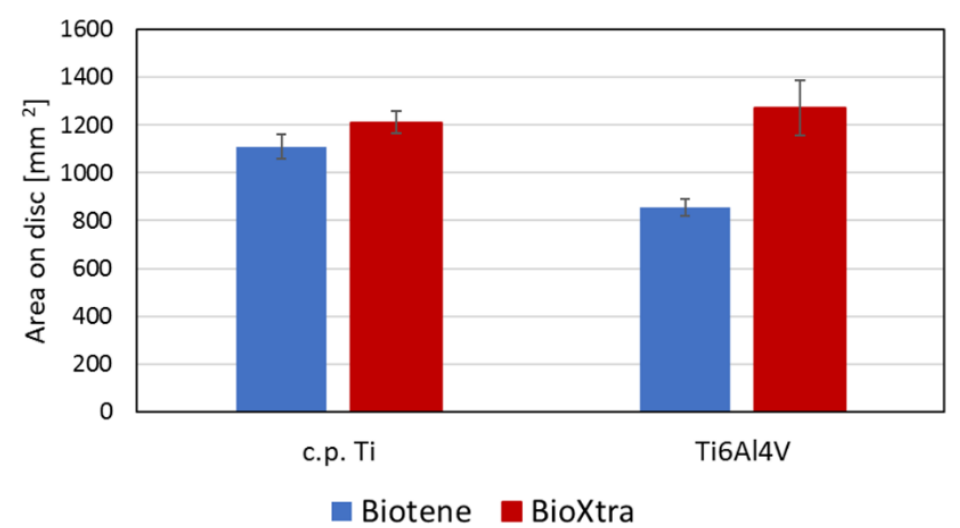

Figure 3. Average areas of the wear scars on the discs.

An image of the wear scars on the zirconia balls was taken at the end of each test and a representative picture is reported below for each tribo-pair in Figure 4. 
Ti c.p.
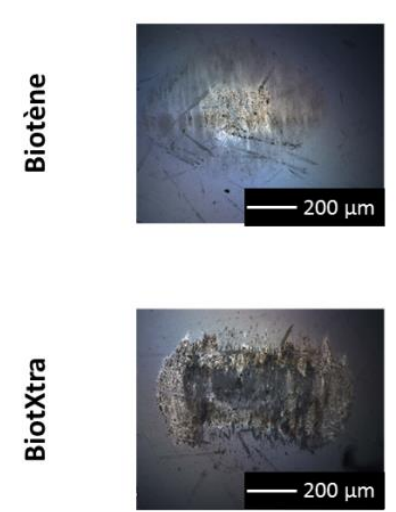

Ti6Al4V alloy
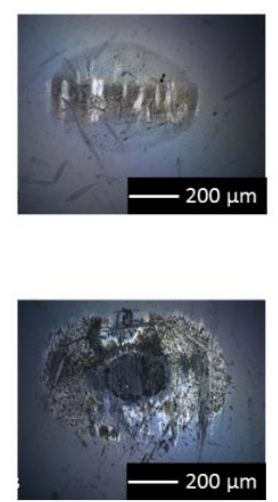

Figure 4. Images of a zirconia balls used against Ti $\mathrm{cp}$ and Ti6Al4V discs after the tests with Biotène and BioXtra.

It can be immediately noticed that the wear tracks on the zirconia balls tested in the presence of Biotène had a similar aspect and the same for those tested with BioXtra. In all cases, the wear scars formed on zirconia balls had an elliptical shape with a darker and more worn-out central area. The occurrence of a strong adhesive interaction between the tribo-pairs lubricated with BioXtra was supported by the higher amount of material transfer on the zirconia balls.

The mean wear scar diameter (MWSD) was calculated by averaging the two main diameters of wear scars on the zirconia ball (Figure 5). The MWSDs registered on Ti c.p. were not statistically different if the scars obtained in the tests with the two different lubricants are compared; no statistical difference also existed between the two substrates tested by using BioXtra as the lubricant. On the other hand, this difference between the MWSDs was statistically significant on Ti6Al4V and if the two substrates tested with Biotène are compared $(p<0.01)$

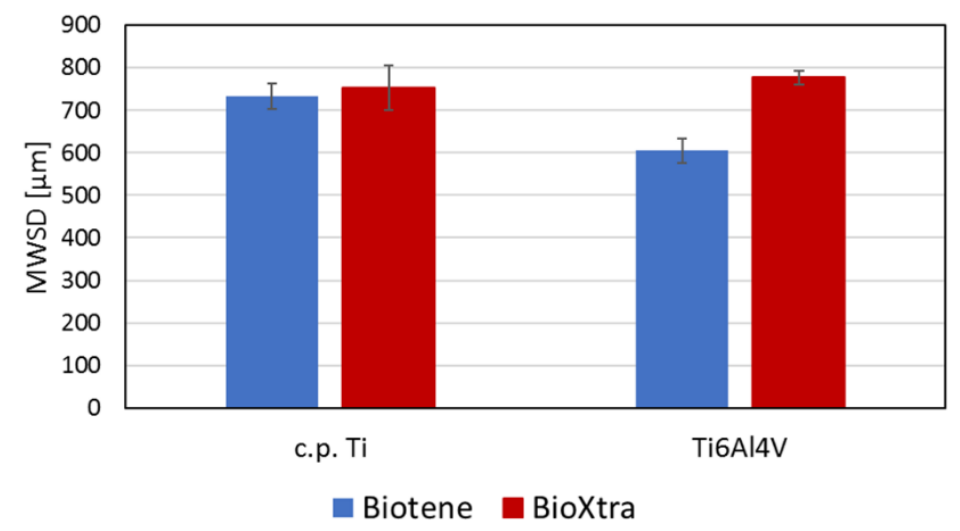

Figure 5. Average mean wear scar diameters on the zirconia balls.

At the end of the tests, the amount of metallic debris dispersed in the artificial saliva used as a lubricant was qualitatively observed (data not reported); once again, the difference between the two salivas was evident with a greater quantity of residues visible at the end of the tests carried out with BioXtra.

It therefore appears that Biotène decreases the wear between the tested materials; this is due first of all to the lower friction coefficient than that in case of BioXtra. Furthermore, the presence in this artificial saliva of organic corrosion inhibitors (surfactants PEG-60 hydrogenated castor oil, cetylpyridinium chloride, and the polymer vp/va copolymer) can justify the lower tendency to wear. In fact, the mechanism of action of organic corrosion inhibitors is based on the adsorption on the surface to form a protective film that protects it against deteriorating [12]. In the presence of BioXtra, a strong 
adhesive interaction has occurred between zirconia and Ti c.p. or the Ti alloy. Hence, the predominant wear mechanism is adhesive galling. It is likely that the surfactants, absent in this artificial saliva and present in Biotène, provide some protection to titanium surfaces from galling.

In this research, in addition to the mechanical tests, the chemical stability of the lubricant film on the titanium surfaces was tested by means of zeta potential titration curves. This is of interest, considering that different $\mathrm{pH}$ values can be present in the mouth and that wettability of the lubricant film and chemical interaction at the lubricant-surface interface are critical in determining the biotribological behaviour. The graphs below (Figure 6) show the zeta potential titration curves of the Ti c.p. and Ti alloy discs after adsorption of the two artificial salivas.
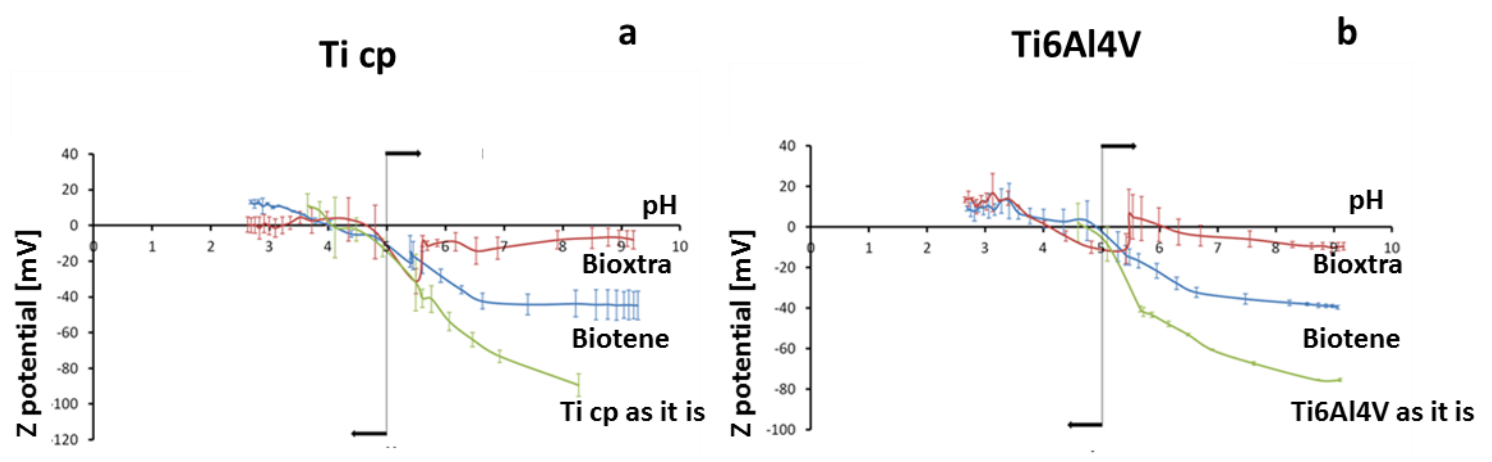

Figure 6. Zeta potential titration curves of Ti c.p. (a) and Ti6Al4V alloy (b) as received (green curves), after adsorption of Biotène (blue curves) and of BioXtra (red curves). The arrows mark the $\mathrm{pH}$ used at the beginning of the measurements and the acidic (on the left) and alkaline (on the right) ranges of the titration.

Comparing the curves of the samples pre-adsorbed with Biotène with the curves of the as-received substrates (i.e., tested without saliva pre-adsorption), we note that the curves obtained on the samples after adsorption were significantly different from the curves of the as-received materials. This means that the adsorption of some compounds from saliva occurred. The slope of the titration curves after adsorption was significantly lower than that of the as-received materials, which means that hydrophilicity of the surfaces after adsorption is higher than that of the bare metals. There was a plateau at $\mathrm{pH}$ higher than 6.5 due to functional groups (such as, for instance, $\mathrm{OH}$ groups) exposed on the surface by the adsorbed compounds, meaning that the functional groups on the surfaces have a specific acidic strength and are all completely dissociated when the $\mathrm{pH}$ is higher than 6.5 , that means that in physiological condition there is a net negative surface charge. According to their dissociation only in the basic range, these groups do not act as a strong acid and they do not significantly affect the isoelectric point on the curve with respect to the Ti as it is (without adsorption of saliva). On the other hand, when strong acidic or alkaline functional groups are present on a surface, they are respectively $\mathrm{de} /$ protonated at lower/higher $\mathrm{pH}$ values than 7 and both the isoelectric point and the onset of the plateau are shifted to the left/right side.

Observing the curves related to the adsorption of BioXtra, it can be said that the curves obtained after adsorption were significantly different from the curves of the as-received materials, which means that the adsorption of saliva compounds also occurred in this case. The adsorbed layer had zeta potential values not far from 0 across the explored range: this behaviour is typical of a super-hydrophilic surface that does not adsorb either $\mathrm{OH}^{-}$or $\mathrm{H}_{3} \mathrm{O}^{+}$ions instead of water molecules, even if the solution is strongly basic or acidic. On the other hand, the curve was not stable with a high standard deviation at some points and fluctuating trend, according to the presence of an un-stable surface layer. In addition, the step registered at pH 5.5 (that is, the first point of the two titration curves in the basic and acidic range) can be related to some instability, or not perfect reproducibility of the adsorbed layer.

These results can be used for interpreting the results obtained from wear tests. Compared to Bioxtra, Biotène decreased the friction coefficient and wear of both substrates because it allows for the 
formation of a chemically stable adsorbed layer with a good hydrophilic behaviour, acting as a good lubricant. On the other hand, the layer formed by BioXtra is not chemically stable and it is not able to act as a good lubricant, even if it has a super-hydrophilic behaviour.

This hypothesis was confirmed by contact angle measurements performed with a water drop on the discs after zeta potential tests, as reported in Figure 7. A consistent decrease in the contact angle with respect to the as-received Ti surfaces (without any adsorption of saliva) was measured on the sample pre-adsorbed with Biotène and used for the zeta potential test, which was in agreement with the zeta potential titration curve where a higher wettability was detected after adsorption of Biotène and confirmed that this saliva was still firmly adsorbed after the electrokinetic zeta potential test. On the other hand, the contact angle was almost unchanged with respect to the as-received titanium surfaces (without any adsorption of saliva) on the sample pre-adsorbed with BioXtra and used for the zeta potential test, confirming that the saliva film was almost completely removed after the electrokinetic zeta potential test and was not stably adsorbed on the titanium surfaces.

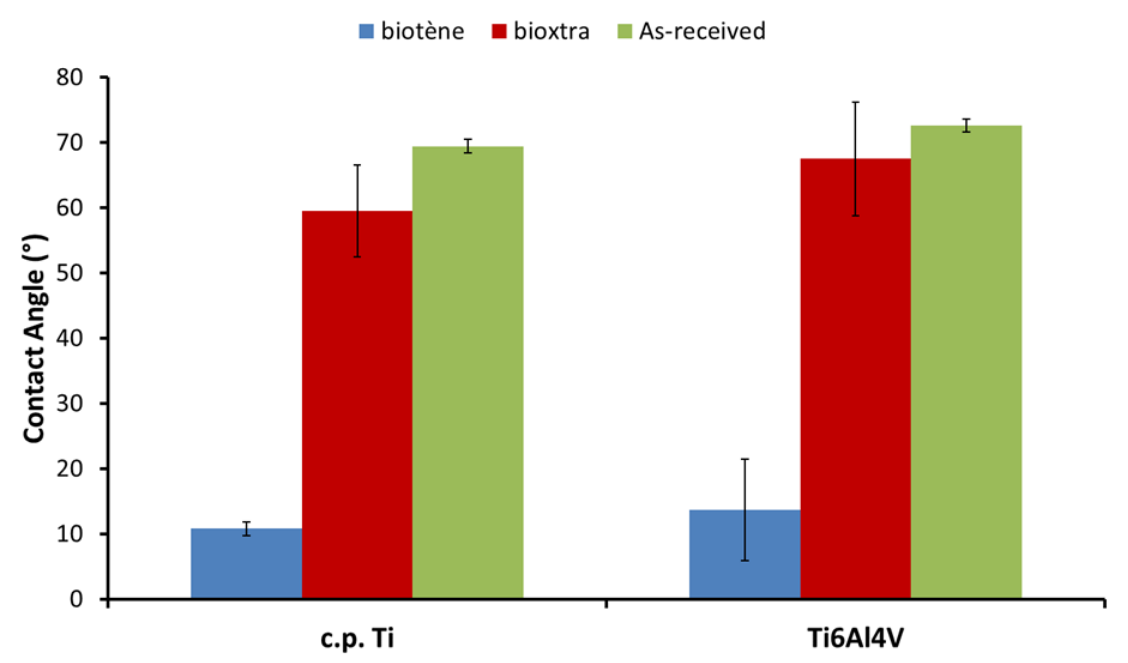

Figure 7. Contact angle measurements of water on Ti c.p. and Ti6Al4V alloy as received and after adsorption of the Biotene and BioXtra artificial salivas.

The obtained results are of interest because they set the relevance of the composition of the selected artificial saliva on the wear resistance of dental materials. Even if this topic has been already partially explored in the literature [13-15], the new evidence derived from this research are here discussed. Friction coefficient and wear were significantly reduced in the presence of organic corrosion inhibitors able to make a chemically and mechanically stable hydrophilic adsorbed layer. First, this means that researchers planning tribological tests have to carefully select the artificial saliva used as a lubricant in order to avoid overestimating the wear resistance of the tested surfaces. Second, it means that patients who need to use artificial saliva and have dental implants have to carefully select the right one. Finally, the use of zeta potential titration measurements is proposed here as a useful experimental tool for obtaining more information for a better understanding of the tribological tests: presence/absence of an adsorbed layer of lubricant on a tribological surface, its chemical and mechanical stability when significant $\mathrm{pH}$ changes occur and a flux of liquid is applied on the surface, the presence of functional groups exposed, and hydrophilicity of the surface after adsorption of the lubricant. The chemical instability of the adsorbed layer of saliva at pH 5.5 in the case of Bioxtra may be relevant in physiological conditions considering that acidic $\mathrm{pH}$ can be easily reached in the oral environment.

On the basis of this research, other investigations will be performed in order to overcome the limitations of the tests previously described including the investigation of the Ti6Al4V-ELI alloy (Gr23) as a substrate because it is currently widely employed in dental applications, better investigation of the adsorbed film thickness, comparison of artificial saliva with different additives (such as the antibacterial 
ones), chemical analysis of the adsorbed compounds, different geometry of the samples, and tribological tests (such as flat-on-flat tests) that better simulate the tribological contact in dental implants.

\section{Conclusions}

Results suggest that the use of an artificial saliva containing organic corrosion inhibitors (such as Biotène) can significantly reduce the friction coefficient and wear both of titanium and zirconia surfaces. This is because it is able to be firmly adsorbed on the surface of the Ti c.p. or Ti6Al4V alloy and form a protective film with high wettability. In the absence of this film (such as in the case of BioXtra), much more severe wear occurs with a galling mechanism. In this last case, the occurrence of a super-hydrophilic saliva film that is not firmly adsorbed on the surface (mainly in an acidic environment) is not efficient in order to avoid severe wear.

From the methodological standpoint, the use of electrokinetic zeta potential and contact angle measurements together with standard tribological tests has shown to be useful for a better understanding of the lubricant action of different artificial saliva on different materials.

This research can be the basis for larger investigations of the tribological behaviour of dental materials and implants in the presence of lubricants with different compositions.

Author Contributions: Conceptualization, F.A., A.T. and S.S.; methodology, F.A. and A.T.; investigation, F.A., A.T. and V.P.; writing — original draft preparation, S.S.; writing—review and editing, S.S.; supervision, S.S. All authors have read and agreed to the published version of the manuscript.

Funding: This research received no external funding.

Acknowledgments: The authors would like to acknowledge Ducom Instruments Europe B.V. for the friction and wear measurements.

Conflicts of Interest: The authors declare no conflict of interest.

\section{References}

1. Zhou, Z.R.; Jin, Z.M. Biotribology: Recent progresses and future perspectives. Biosurf. Biotrib. 2015, 1, 3-24. [CrossRef]

2. Zheng, J.; Zhou, Z.-R. Oral Tribology. In Encyclopedia of Tribology; Wang, Q.J., Chung, Y.-W., Eds.; Springer: Boston, MA, USA, 2013.

3. Branco, A.C.; Moreira, V.; Reis, J.A.; Figueiredo-Pina, C.G.; Serro, A.P. Influence of contact configuration and lubricating conditions on the microtriboactivity of the zirconia-Ti6Al4V pair used in dental applications. J. Mech. Behav. Biomed. Mat. 2019, 91, 164-173. [CrossRef] [PubMed]

4. De Almeida, P.V.; Gregio, A.; Machado, M.; de Lima, A.; Azevedo, L.R. Saliva composition and functions: A comprehensive review. J. Contemp. Dent. Pract. 2008, 9, 72-80.

5. Heller, D.; Helmerhorst, E.J;; Oppenheim, F.G. Saliva and serum protein exchange at the tooth enamel surface. J. Dent. Res. 2017, 96, 437-443. [CrossRef] [PubMed]

6. Macakova, L.; Yakubov, G.; Plunkett, M.A.; Stokes, J.R. Influence of ionic strength changes on the structure of pre-adsorbed salivary films. A response of a natural multi-component layer. Coll. Surf. B Biointerfaces 2010, 77, 31-39. [CrossRef] [PubMed]

7. Harvey, N.M.; Carpenter, G.H.; Proctor, G.B.; Klein, J. Normal and frictional interactions of purified human statherin adsorbed on molecularly-smooth solid substrata. Biofouling 2011, 27, 823-835. [CrossRef] [PubMed]

8. Stimmelmayr, M.; Sagerer, S.; Erdelt, K.; Beuer, F. In vitro fatigue and fracture strength testing of one-piece zirconia implant abutments and zirconia implant abutments connected to titanium cores. Int. J. Oral Maxillofac. Implant. 2013, 28, 488-493. [CrossRef] [PubMed]

9. Gehrke, P.; Johannson, D.; Fischer, C.; Stawarczyk, B.; Beuer, F. In vitro fatigue and fracture resistance of oneand two-piece CAD/CAM zirconia implant abutments. Int. J. Oral Maxillofac. Implant. 2014, 30, 546-554. [CrossRef] [PubMed]

10. Mizumoto, R.M.; Malamis, D.; Mascarenhas, F.; Tatakis, D.N.; Lee, D.J. Titanium implant wear from a zirconia custom abutment: A. clinical report. J. Pros. Dent. 2019, in press. 
11. Sikora, C.L.; Alfaro, M.F.; Yuan, J.C.-C.; Barao, V.A.; Sukotjo, C.; Mathew, M.T. Wear and corrosion interactions at the titanium/zirconia interface: Dental implant application. J. Prosthodont. 2018, 27, 842-852. [CrossRef] [PubMed]

12. Brycki, B.E.; Kowalczyk, I.H.; Szulc, A.; Kaczerewska, O.; Pakiet, M. Organic Corrosion Inhibitors. In Corrosion Inhibitors, Principles and Recent Applications; Aliofkhazraei, M., Ed.; Tarbiat Modares University: Tehran, Iran, 2017.

13. Vilhena, L.; Oppong, G.; Ramalho, A. Tribocorrosion of different biomaterials under reciprocating sliding conditions in artificial saliva. Lubr. Sci. 2019, 31, 364-380. [CrossRef]

14. Li, C.; Liang, R.; Ren, J.; Wang, J.; Xun, Y.; Meng, H.; Sun, S. Comparative study on friction properties of different dental restorative materials against natural tooth enamel and dentin. J. Mat. Res. 2016, 30, 489-495.

15. Borrás, A.D.; Buch, A.; Cardete, A.R.; Navarro-Laboulais, J.; Muñoz, A.I. Chemo-mechanical effects on the tribocorrosion behavior of titanium/ceramic dental implant pairs in artificial saliva. Wear 2019, 426-427, 162-170. [CrossRef]

(C) 2020 by the authors. Licensee MDPI, Basel, Switzerland. This article is an open access article distributed under the terms and conditions of the Creative Commons Attribution (CC BY) license (http://creativecommons.org/licenses/by/4.0/). 